\title{
Policy measures to promote mid-summer drainage in paddy fields for a reduction in methane gas emissions: the application of a dynamic, spatial computable general equilibrium model
}

\author{
Yoji Kunimitsu' ${ }^{1}$ D $\cdot$ Motoki Nishimori $^{2}$
}

Received: 6 September 2018 / Revised: 29 August 2019 / Accepted: 7 September 2019 / Published online: 21 September 2019

(c) The Author(s) 2019

\begin{abstract}
Rice production is affected by climate change, while climate change is simultaneously accelerated by methane gas $\left(\mathrm{CH}_{4}\right)$ emissions from paddy fields. The rice sector must take suitable mitigation measures, such as prolonging mid-summer drainage (MSD) before the rice flowering period. To propose a mitigation policy, this study aims to demonstrate the environmental and economic effects of MSD in Japanese paddy fields by using a dynamic, spatial computable general equilibrium (CGE) model and crop model; the study also considers environmental subsidies with a carbon tax scheme to promote MSD measures. The results demonstrate that climate change under the 8.5 representative concentration pathway (RCP) scenario will reduce rice prices and rice farmers' nominal income due to bumper harvests until the 2050s. Promoting MSD in paddy fields can prevent a decrease in farmers' nominal income and effectively reduce $\mathrm{CH}_{4}$ emissions if all farmers adopt this measure. However, some farmers can potentially increase their own yield by avoiding MSD under high rice prices, which would be maintained through other farmers' participation. A strong motivation exists for some farmers to gain a "free ride," and an environmental subsidy with a carbon tax can help motivate farmers to adopt MSD. Therefore, the policy mix of prolonging MSD and environmental subsidies can increase all farmers' incomes by preventing "free rides" and decrease greenhouse gas emissions with a slight decrease in Japan's GDP.
\end{abstract}

Keywords Environmental subsidy with carbon tax $\cdot$ Crop model $\cdot$ Representative concentration pathway (RCP) scenario · Free ride $\cdot$ Nominal gross revenue

\section{Introduction}

Rice production highly depends on climate conditions, including temperature, solar radiation, and precipitation. Future climate change will affect rice production, while greenhouse gas (GHG) emissions from rice production will simultaneously accelerate the warming process. Methane $\left(\mathrm{CH}_{4}\right)$ is the second-largest GHG in terms of abundance in the Earth's atmosphere, and $\mathrm{CH}_{4}$ emissions from paddy fields account for more than $10 \%$ of worldwide $\mathrm{CH}_{4}$

Yoji Kunimitsu

ykuni@affrc.go.jp

1 Institute for Rural Engineering, National Agriculture and Food Research Organization, 2-1-6 Kannondai, Tsukuba, Ibaraki 305-8609, Japan

2 Institute for Agro-Environmental Sciences, National Agriculture and Food Research Organization, 3-1-3 Kannondai, Tsukuba, Ibaraki 305-8604, Japan emissions. As these numbers are not ignorable, the rice sector must take suitable mitigation measures to decrease $\mathrm{CH}_{4}$ emissions and tackle future climate change. Further, it is crucial to quantify the economic effects of reducing $\mathrm{CH}_{4}$ in creating better policy measures from both the environmental and economic perspectives.

Mid-summer drainage (MSD) before the rice flowering period generates cracks in paddy fields and introduces air to the root zone (Fig. 1). Such aeration increases the rice yield and decreases the total $\mathrm{CH}_{4}$ production from paddy fields; however, an excessively long MSD period decreases rice production, in spite of an additional reduction in $\mathrm{CH}_{4}$ emissions (Itoh et al. 2011). This is one trade-off in prolonging MSD. Naturally, farmers are not obliged to participate in MSD, as the cultivation of rice began thousands of years ago, before the start of climate change. Additionally, ceasing rice production does not solve the problem, because most paddy fields could turn to swamp and still continue to emit $\mathrm{CH}_{4}$. Considering this background and the trade-off effects, 
Fig. 1 MSD implementation and its effects. Note: The signs on the horizontal axis indicate the location of survey fields; "Y," "F," "N," "G," "A," "T," "KM," and "KG" represent the Yamagata, Fukushima, Niigata, Gifu, Aichi, Tokushima, Kumamoto, and Kagoshima prefectures, respectively. Source: Itoh et al. (2011)

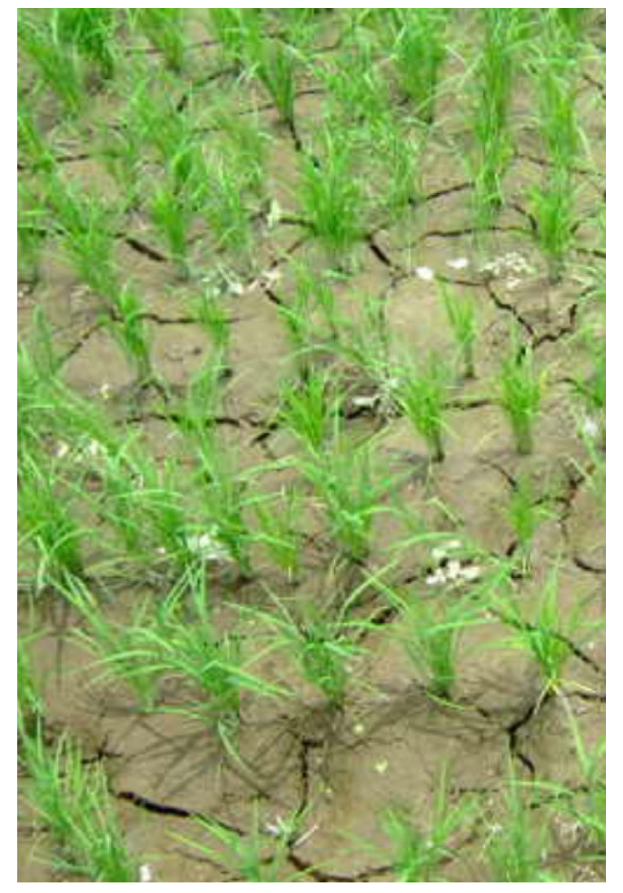

(a) Changes in $\mathrm{CH}_{4}$ emissions (\%)

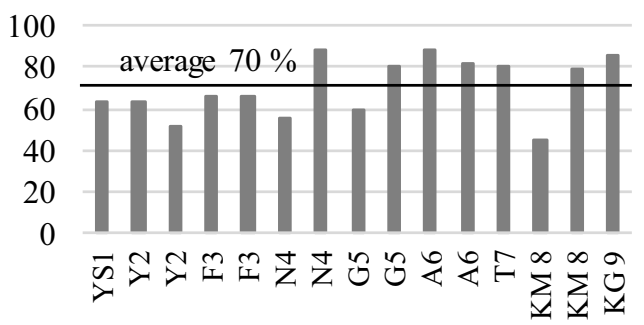

(b) Changes in rice yield (\%)

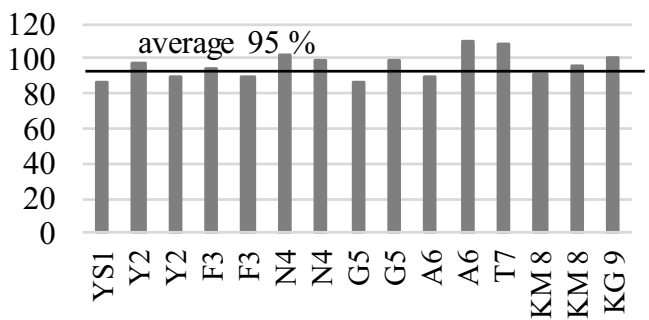

incentives for farmers must be introduced to encourage their cooperation.

This study aims to quantify the effects of both prolonging the MSD period and offering environmental subsidies with a carbon tax as mitigation measures by using a dynamic, spatial computable general equilibrium (CGE) model. When future situations are simulated, (i) projection results from global climate and crop yield models are used, (ii) the tradeoff effects of MSD and the compensation effects of environment subsidies with a carbon tax are concretely quantified, and (iii) regional differences are considered.

The rest of this paper is organized as follows: "Literature review and scientific questions" section reviews previous studies on CGE analyses to evaluate climate change. "Method" section explains the analytical methods. "Results" section shares the results of several simulations using the CGE model, and the final section concludes and discusses policy implications.

\section{Literature review and scientific questions}

Itoh et al. (2011) measured the trade-off effects of MSD from field surveys in several regions in Japan and compared prolonging the MSD period for one more week against the conventional period (Fig. 1). Their data indicated that an additional MSD period decreased $\mathrm{CH}_{4}$ emissions by $30 \%$ on average (11-55\%), but decreased rice yields by $5 \%$ (from a $14 \%$ decrease to a $10 \%$ increase). If all farmers assumed this MSD measure, 1.67 million tons of $\mathrm{CH}_{4}$ could be reduced annually throughout Japan. This number is $30 \%$ of total
$\mathrm{CH}_{4}$ emissions or equal to 5.57 million tons of $\mathrm{CO}_{2}$ from all paddy fields in Japan.

In terms of future rice production, previous studies using a rice crop model indicate that the initial high levels of rice yields will eventually decline at summer temperatures of higher than $28^{\circ} \mathrm{C}$; such a change will be especially obvious in western Japan after the 2040s (Iizumi et al. 2009). Further, Kunimitsu et al. (2015) used the rice crop model's projection results to analyze the causative factors for total factor productivity (TFP), which is a comprehensive productivity index, in Japanese rice production under climate change conditions. Consequently, (i) temperature and solar radiation were shown to have high potential impact on rice yields, next to economies of scale, as represented by each farm organization's farm management scale, and (ii) both climate and socioeconomic factors were shown to widen regional gaps in rice TFP over time.

The economic influences of future climate change in the global food market were analyzed by an econometric model (Furuya et al. 2014). The model's rice yield function was estimated by considering the temperature and precipitation during the rice maturation period. The simulation results indicated that a future temperature increase would increase rice production in most Asian countries, including Japan, but excess temperatures would have negative effects. This previous study focused on future agricultural productivity, but could not fully capture the feedback effects from other markets and agents. Thus, a macroeconomic analysis with a general equilibrium framework is needed to evaluate policy measures under resource restrictions and by considering government sectors. 
The CGE model depicts inter-market relations and trade flows in the economy as a whole and considers the circular flow of income and expenditures under limited resources. Therefore, CGE models are better suited for analyzing global effects on agricultural markets and policy issues, as is the case with climate change (Masui 2005; Palatnik and Roson 2012; Kunimitsu 2018). Further, Lee (2009) used a multisector CGE model to analyze the impact of climate change on global food prices and quantities; his analysis revealed that climate change benefited developed countries in their crop yields, but negatively influenced developing countries. Calzadilla et al. (2011) used a CGE model to analyze the effects of climate change on agriculture relative to water use. Their results indicated that climate change had mostly positive effects on social welfare in water-stressed regions, but these influences were more complicated, and mostly negative, in regions in which water was not scarce. Kunimitsu (2015) also analyzed the influences of climate change on the Japanese economy with a CGE model. This study demonstrated that until the 2040s, future climate change would increase rice production, but decrease farmers' income due to substantial price decreases.

Regarding mitigation and adaptation measures, the CGE model was also used to evaluate carbon tax and $\mathrm{CO}_{2}$ emissions trading. Most previous studies note that these instruments decreased carbon emissions with relatively little economic distortion (Ekins and Barker 2001), but in reality, only a few countries adopted these measures. Further, other tax reductions or environmental subsidies that use carbon tax revenues can potentially create economic profit; this is called the "double-dividend hypothesis." Regarding Japanese environmental policy, Kawase et al. (2003) noted a positive effect from decreasing social insurance premium payments through carbon tax revenues, supporting the double-dividend hypothesis. In contrast, Takeda (2007) mentioned that a decrease in labor or income taxes through carbon tax revenues created no profits in Japan, as labor and income taxes were less distortionary than others. These different effects from the double-dividend hypothesis likely depend on the policy measures in which the carbon tax revenues are used.

As these previous studies indicate, CGE models have great potential in evaluating the effects of environmental policy measures and considering resource limitations. However, few studies focus on the economic ripple effects of the measures to decrease $\mathrm{CH}_{4}$ emissions. As little room exists for $\mathrm{CO}_{2}$ reduction in Japan, it is useful to consider decreasing $\mathrm{CH}_{4}$ emissions and evaluate the use of MSD and environmental subsidies with a carbon tax as potential environmental policy measures.

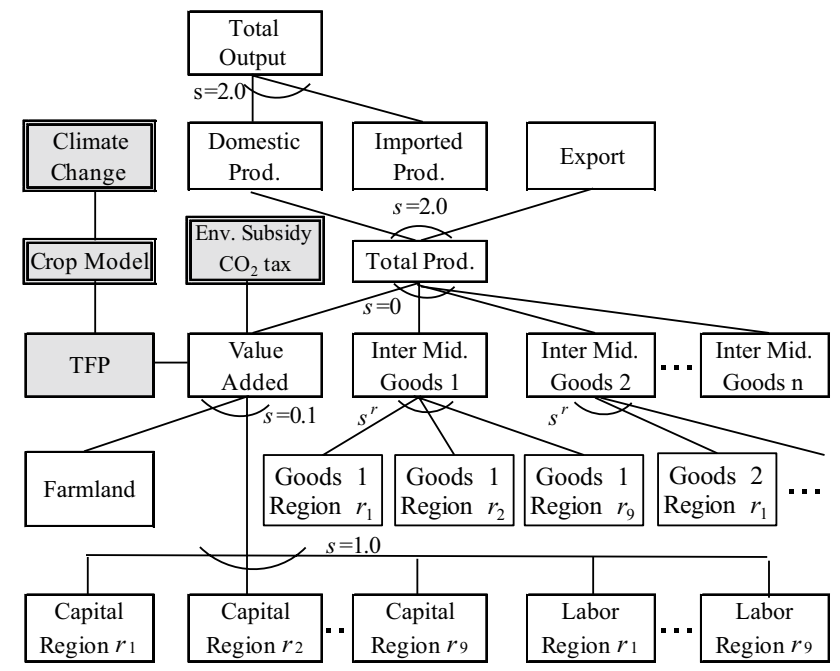

Fig. 2 Structure of production inputs. Note: The $s$ here indicates the substitution elasticities in the CES function, and $s^{r}$ indicates the spatial substitution elasticities

\section{Method}

\section{Structure of the recursive-dynamic spatial CGE model}

The model used here is the recursive-dynamic CGE model with considering inter-regional relationships ${ }^{1}$ this model's structure is based on work by Ban (2007) and Kunimitsu (2015). ${ }^{2}$ The major deviations from the original model are as follows.

The cost functions, as derived from the production functions, are formed as a nested type of CES (constant elasticity of substitution) function (Fig. 2). These functions are based on the firms' optimization behavior. The bottom part of added value composed of capital and labor is Cobb-Douglas type function which is commonly used in the previous studies. Farmland is then joined to production with consideration of low substitutability against capital and labor (Kunimitsu 2015). Intermediate inputs and value-added production create total production with Leontief type functional form. After calculating total production, imports and exports are,

\footnotetext{
1 The model in this paper is "spatial" rather than "regional," as it has a spatial linkage structure among multiple regions by considering the flexibility of inter-regional trade, which is primarily represented by spatial substitution elasticity (Miyagi 2012).

2 The model employed here uses GAMS (GAMS Development Corporation) and MPSGE (a modeling tool using the mixed complementary problem) developed by Rutherford (1999). The source code of the model was published in Kunimitsu (2015), so concrete equations of the model were omitted here.
} 


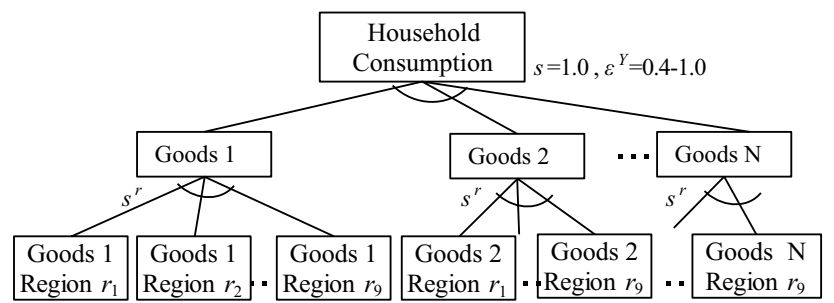

Fig. 3 Structure of consumption demands. Note: The $s$ and $s^{r}$ are the same as those in Fig. $2 ; \varepsilon^{Y}$ denotes the income elasticity of consumption

respectively, defined by the Armington's function and the CET (constant elasticity of transformation) function.

The prices of each industry in the region are assumed to have different prices, because some products produced in different regions have discriminatory prices in the market. Hence, the same industrial goods and services produced in other regions are traded and used for production. The market's degrees of regional differentiation depend on the flexibility of inter-regional trade, represented by the spatial substitution elasticity $\left(s^{r}\right)$ as illustrated in Fig. 2. Tsuchiya et al. (2005) empirically showed these spatial substitution elasticity values were between 0.40 and 8.0 , while Koike and Naka (2014) used each Japanese industry's data to discover that these values differed according to the industry, and most had values of approximately 1 . Their estimations are smaller than Armington's substitution elasticity noted in GTAP database for foreign trade (Narayanan and Walmsley 2008). Therefore, the supply chain's domestic structure is assumed as less flexible than the foreign trade structure.

Consumption is also defined by the nested function based on consumers' maximization assumptions on utility (Fig. 3). The first nest is defined by the function of the LES (linear expenditure system), as derived from the Stone-Geary utility function. The second nest reflects spatial flexibility among the commodities produced in different regions with the spatial substitution elasticity $\left(s^{r}\right)$. Other structures-such as government decision and taxation scheme other than carbon tax-are the same as Kunimitsu (2015) study.

\section{Conjunction function of climate factors in the CGE model}

Climate factors are assumed to influence rice production through the rice total factor productivity (TFP). Based on Kunimitsu et al. (2015), the TFP function to be estimated is:

$$
\begin{aligned}
\ln \left(\mathrm{TFP}_{r, t}\right)= & \beta_{0}+\beta_{1} \ln \left(\mathrm{MA}_{r, t}\right)+\beta_{2} \ln \left(\mathrm{KK}_{t}\right)+\beta_{3} \ln \left(\mathrm{CHI}_{r, t}\right) \\
& +\beta_{4} \ln \left(\mathrm{CQI}_{r, t}\right)+\beta_{5} \ln \left(\mathrm{CFI}_{r, t}\right)+\varepsilon_{r, t}+\rho \varepsilon_{r, t-1},
\end{aligned}
$$

where $\mathrm{TFP}_{r, t}$ is the total factor productivity in year $t$ and region $r$; MA is the management area per farm organization,
Table 1 Estimation results of TFP function (Eq. 1)

\begin{tabular}{lll}
\hline Items & Coefficient & $t$-statistic \\
\hline Constant & -0.4403 & $-5.1^{* * *}$ \\
$\ln (\mathrm{MA})$ & 0.3240 & $9.7^{* * *}$ \\
$\ln (\mathrm{KK})$ & 0.1409 & $6.8^{* * *}$ \\
$\ln (\mathrm{CHI})$ & 0.2945 & $12.7^{* * *}$ \\
$\ln (\mathrm{CQI})$ & 0.0878 & $5.9^{* * *}$ \\
$\ln (\mathrm{CFI})$ & -0.0232 & $-4.5^{* * *}$ \\
$\rho$ for first-order serial correlation & 0.5442 & $19.7^{* * *}$ \\
Adjusted $R^{2}$ & 0.851 & \\
Log-likelihood & 1223 & \\
AIC & -2.068 & \\
$F$-statistics & $152.1^{* * *}$ & \\
Chi-squared statistic & $30.9^{* * *}$ & \\
\hline
\end{tabular}

Data used here consist of 38 prefectures and over 31 years (1979 to 2010 except for 1993 when extremely cold weather happened in Japan). A fixed-effects model was adopted in light of the Hausman (Chi-squared) test statistic, and a first-order auto-regressive error term was assumed because of the relatively high serial correlation of the residuals in the ordinal least squares estimations

representing economies of scale; KK represents the knowledge capital stocks accumulated through research and development (R\&D) investments; $\mathrm{CHI}$ is the rice yield index; $\mathrm{CQI}$ is the rice quality index; CFI is the flood index caused by heavy rain; $\beta$ 's are the parameters to be estimated, corresponding to elasticities of TFP; $\rho$ is also a parameter to be estimated, representing the first-order auto-regressive process in the error term; and $\varepsilon$ denotes the error term. Further, CHI, CQI, and CFI are estimated only by climate conditions-such as temperature, solar radiation, and precipitation-using the crop yield model, crop quality model, and extracted maximum precipitation from August to October, respectively ("Appendix"). Table 1 displays the estimation results, using panel data.

Moreover, MA and KK are assumed as constant during the simulation periods to simplify the simulation. By dividing both sides of Eq. (1) with the referenced year, which is the starting year in our simulation $\left(t_{0}=2015\right)$, the following conjunction equation for TFP is derived:

$$
\begin{aligned}
& \mathrm{TFP}_{r, t} / \mathrm{TFP}_{r, t_{0}}=\left(\mathrm{CHI}_{r, t} / \mathrm{CHI}_{r, t_{0}}\right)^{\beta_{3}} \\
& \quad \cdot\left(\mathrm{CQI}_{r, t} / \mathrm{CQI}_{r, t_{0}}\right)^{\beta_{4}} \cdot\left(\mathrm{CFI}_{r, t} / \mathrm{CFI}_{r, t_{0}}\right)^{\beta_{5}} .
\end{aligned}
$$

\section{Resource allocation function}

The total labor supply fundamentally decreases according to changes in the Japanese population, but the regional labor force as a supply source is assumed to move across regions based on wage differences. The labor supply (LS) is defined as: 
$\mathrm{LS}_{r, t}=\mathrm{LS}_{r, t-1}\left(\frac{w_{r, t-1}}{\bar{w}_{t-1}}\right)^{0.5} \frac{\mathrm{POP}_{r, t}}{\mathrm{POP}_{r, t-1}}$,

where $w$ is the wage rate; $\bar{w}$ is the entire country's average wage rate; $\mathrm{POP}_{t} / \mathrm{POP}_{t-1}$ indicates the population's growth rate; and 0.5 is the wage elasticity of labor supply considering the relatively inflexible Japanese labor market, which is characterized by low female labor participation rate, low mid-career adoption rate, and high persistence to the original living location (Kunimitsu et al. 2015).

Private capital stocks KP are accumulated through private investments:

$\mathrm{KP}_{r, t}=(1-\delta) \mathrm{KP}_{r, t-1}+\mathrm{IP}_{t}$.

Here, $\delta$ is the depreciation rate and is set at an actual rate of $4.0 \%$; this was calculated using national accounting statistics from 2005 to 2013. Further, private investments (IP) are assumed as allocated to industries according to the rate of return (ROR):

$\mathrm{IP}_{i, r, t}^{*}=\mathrm{IP}_{i, r, t-1}\left(\frac{\mathrm{PK}_{i, r, t-1} \cdot \mathrm{ROR}_{i, r, t-1}}{\overline{\mathrm{PK}}_{r, t-1} \cdot \overline{\mathrm{ROR}}_{r, t-1}}\right)^{0.5} \frac{\mathrm{IPT}_{r, t}}{\mathrm{IPT}_{r, t-1}}$,

$\mathrm{IP}_{i, r, t}=\frac{\mathrm{IP}_{i, r, t}^{*}}{\sum_{r} \mathrm{IP}_{i, r, t}^{*}} \mathrm{IPT}_{r, t}$,

The subscript $i$ here indicates the industry; IP* is the ideal private investment; $\mathrm{PK}$ is the capital service price changing the real ROR to a nominal value; IPT is the total private investment, regulated by the total savings under a macroeconomic balance; and 0.5 is the price elasticity of investments, assuming an inelastic reflection of investors under the existence of transaction costs as explained by Kunimitsu et al. (2015).

Farmland has decreased under the pressure of urbanization and imported agricultural products in addition to progress of depopulation in rural areas. However, to express these pressures is difficult in a model, so the total farmland supply FS is assumed to decrease with the past trend:

$\mathrm{FS}_{r, t}=\left(1+g f_{r} / 100\right) \mathrm{FS}_{r, t-1}$,

where $g f_{r}$ is the annual change rate of farmland by regions.

\section{Environmental subsidies with a carbon tax}

To secure funds for prolonging MSD period, a carbon tax is assumed and levied on all industries to maintain the balance of national accounts. The environmental subsidy is set to match the monetary value of $\mathrm{CH}_{4}$ reduced by prolonging the MSD period, and its value $\left(V_{\mathrm{CH} 4}\right)$ is:

$V_{\mathrm{CH} 4}=25 \cdot P_{\mathrm{CO} 2} \cdot O_{\mathrm{CH} 4} \cdot r_{\mathrm{CH} 4}$, where 25 is the carbon equivalent coefficient for $\mathrm{CH}_{4}$ emissions; $P_{\mathrm{CO} 2}$ is the carbon price realized in the carbon trade market; $O_{\mathrm{CH} 4}$ is the total amount of $\mathrm{CH}_{4}$ produced from paddy fields in Japan; and $r_{\mathrm{CH} 4}$ is the reduction rate by prolonging MSD period.

A carbon tax is subsequently set so that the carbon tax revenue matches to the above expenditure for environmental subsidies. The environmental tax levied on each industry (Taxc) in accordance with $\mathrm{CO}_{2}$ emissions is:

$T \operatorname{axc}_{i, r}=\frac{V_{\mathrm{CH} 4}}{O_{\mathrm{CO} 2}} \mathrm{e}_{-} \mathrm{co} 2_{i} \cdot y_{i, r}$,

where $O \mathrm{co} 2$ is the total amount of $\mathrm{CO}_{2}$ emitted from all industries (so that $V_{\mathrm{CH} 4} / O_{\mathrm{CO} 2}$ corresponds to the unit price of carbon tax); e_co2 is the emission coefficient estimated by National Institute for Environmental Study (NIES) (2019); and $y$ is each industry's total production value.

\section{Data to calibrate the CGE model}

A social accounting matrix was used to calibrate the model's parameters, based on Japan's 2014 inter-regional input-output table which was estimated from the interregional input-output data in 2005 (Ministry of Economy, Trade and Industry (METI) 2010). Updated inter-regional input-output data were calculated by using the RAS method, which is a mathematical procedure for balancing the columns and rows of modified input-output table, and the controlled total production that was measured from national accounts' statistics in 2005 and 2014 (Cabinet Office of Japan 2016). Rice production was more precisely analyzed by separating the rice sector from the agricultural sector in the original table using information from the 2005 national input-output basic classification table, which included $404 \times 350$ sectors (Ministry of Economy, Trade and Industry (METI) 2009). The original sectors were then reassembled into 20 sectors: (1) rice paddies (pady); (2) other cultivated plants (ocpl); (3) livestock (livs); (4) agricultural services (agsv); (5) forestry, fishery, and mining (ofst); (6) rice milling (rice); (7) noodles, bread, and other milling (omil); (8) dairy and meat products (mkmt); (9) other food and drinks (ofnd); (10) chemical products (chem); (11) machinery (mach); (12) electrical equipment (elem); (13) other manufacturing (omfg); (14) construction (cnst); (15) electricity, gas, and water (elgw); (16) wholesale and retail sales (trad); (17) financial services (fina); (18) transportation and telecommunication (tpts); (19) research and education (rese); and (20) other services (sev).

Nine regions were included: Hokkaido (1hok); Tohoku (2toh); Kanto (3kan), including Niigata Prefecture; Chubu (4chb); Kinki (5kin); Chugoku (6chg); Shikoku (7sik); Kyushu (8kyu); and Okinawa (9oki) (Fig. 4). 


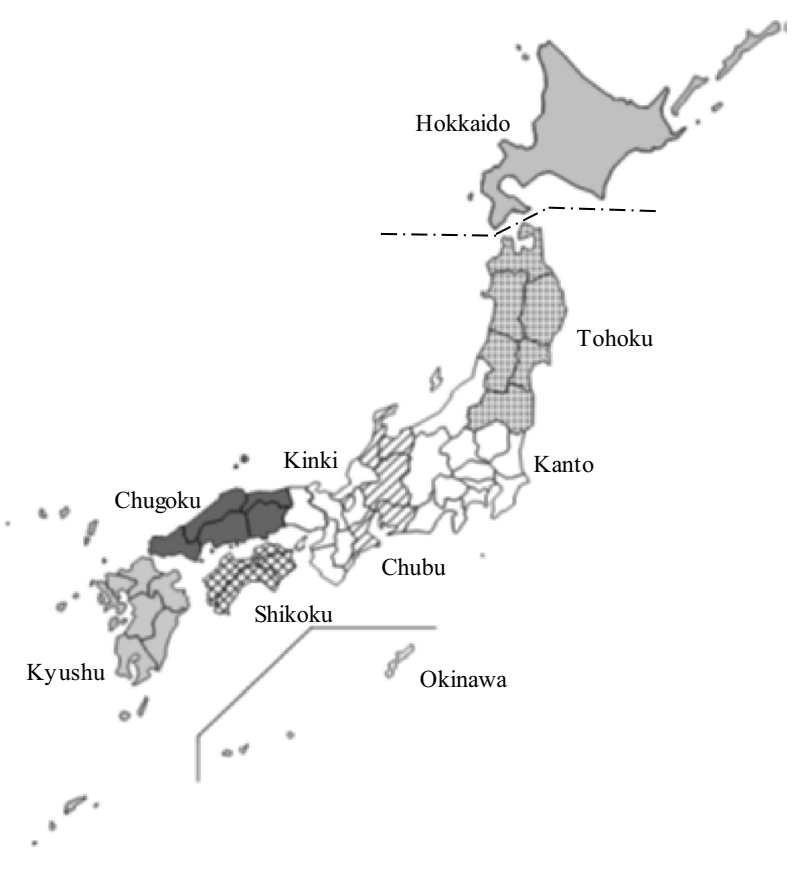

Fig. 4 Areas used in the CGE model

The input value of farmland is not noted in the Japanese input-output table, but was estimated by each year's areas of cultivated farmland (Ministry of Agriculture, Forestry and Fisheries (MAFF) 2009), by multiplying the areas with farmland rent. The value of this farmland was then subtracted from the operation surplus in the input-output table, and the remaining operation surplus was added to the value of capital input (the depreciation of capital stocks).

The annual change rate of farmland, $g f_{r}$, in Eq. (7) is measured using the 2008-2017 trends based on cultivated farmland statistics (Ministry of Agriculture, Forestry and Fisheries (MAFF) 2009). The concrete annual change rate is $-0.2 \%$ in Hokkaido; $-0.4 \%$ in Tohoku; $-0.5 \%$ in Chubu, Kinki, and Okinawa; $-0.6 \%$ in Kanto and Kyushu; $-0.7 \%$ in Chugoku; and $-0.9 \%$ in Shikoku.

The spatial substitution elasticities, $s^{r}$, of inter-regional trade for intermediate inputs (Fig. 1) were obtained from the empirical estimations (Koike and Naka 2014). The concrete values of spatial substitution used here were 1.22 for food processing industries ("rice," "omil," “mkmt," "ofnd"), 1.32 for chemical industry ("chem"), 1.238 for machinery industry ("mach"), 1.348 for electrical equipment industry ("elem"), and 1.242 for other manufacturing industry ("omfg"). The remaining industries adopt 1 for the substitution elasticity, as it shows moderate substitutability and is close to the average of all of Koike and Naka's estimations.

The spatial substitution elasticities in the consumption part (Fig. 2) are the same as intermediate inputs based on empirical study. The Frisch parameter for LES function is -1.2 based on the Saito's (1996) empirical study. Other substitution elasticities were the same as Kunimitsu (2015) which was based on GTAP database. To secure the stability of the simulation, a sensitivity analysis with $\pm 20 \%$ change of the most substitution elasticities was conducted. That analysis confirmed that the direction did not change although the simulation results' levels changed.

\section{Simulation method}

The following cases are considered in measuring the influences of climate change and mitigation measures:

Case 0 (Reference case): This case represents a baseline reference situation. In this case, the TFP of rice production is set to one, indicating no technological progress and no changes in climate conditions.

Case 1 (only climate change): This case represents the future climate change that only affects rice production, but does not consider mitigation measures. The levels of future rice TFP are calculated using Eq. (2). Changes in annual climate factors are projected by the crop growth model (Eq. 10), crop quality model (Eq. 11), and maximum precipitation (Eq. 12). Regarding the inputs of these equations, the projection results for climate conditions - such as solar radiation, temperature, and precipitation - are obtained from a global climate model, MIROC version 5 (K-1 Model Developers 2004). The GHG emissions scenario involves representative concentration pathways of 8.5 (RCP 8.5), which indicates the highest increase in future temperatures among the RCP scenarios. ${ }^{3}$ The global average temperature in this scenario increases by 2.6 to $4.8^{\circ} \mathrm{C}$ by 2100 .

Case 2 (voluntary MSD under climate change): This case considers prolonging the MSD period under the future RCP 8.5 scenario. All rice farmers voluntarily prolong MSD by one more week and accept a 5\% decrease in rice yields to decrease paddy fields' $\mathrm{CH}_{4}$ emissions by $30 \%$ (statistics that are based on Fig. 1).

Case 3 (MSD and environmental subsidies with a carbon tax, mixed policy): This case considers prolonging MSD and environmental subsidies with a carbon tax under climate change to motivate farmers. Environmental subsidies are provided to only farmers who decrease their paddy fields' $\mathrm{CH}_{4}$ emissions by prolonging MSD. Values of environmental subsidies are calculated by Eq. (8). ${ }^{4}$ Also, based

\footnotetext{
${ }^{3}$ For comparison, simulations involving future climate change under the RCP 4.5 scenario were conducted, but the policy measures' effects were nearly the same as in the RCP 8.5 scenario, although the climate change effects differed. This is because calculating the differences between each case and reference case cancels out the influence of climate conditions.

4 The total monetary value of $\mathrm{CH}_{4}\left(V_{\mathrm{CH} 4}\right)$ is $\$ 1333$ million $(25 \times$ $31.9 \times 5.57 \times 10^{6} \times 0.3 \times 10^{-6}$ ), where $\$ 31.9$ per ton (or $€ 27.0$ or 3510 yen per ton) is the unit price $\left(P_{\mathrm{CO} 2}\right)$ for the environmental subsidy, which is the actual carbon price realized in the European carbon trade market $2019,5.57 \times 10^{6}$ ton is the total amount of $\mathrm{CH}_{4}\left(O_{\mathrm{CH} 4}\right)$ produced from paddy fields in all over Japan, and 0.3 is the reduction rate $\left(r_{\mathrm{CH} 4}\right)$ from prolonging MSD.
} 
Fig. 5 Changes in regional TFP under future climate change. Note: In the legend, " 1 hok" is Hokkaido, "2toh" is Tohoku, " 3 kan" is Kanto, " 4 chb" is Chubu, "5kin" is Kinki, "6chg" is Chugoku, "7sik" is Shikoku, " $8 \mathrm{kyu}$ " is Kyushu, and "9oki" is Okinawa

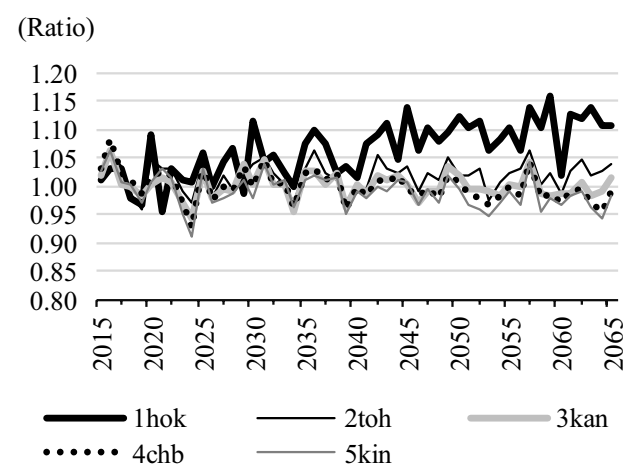

(Ratio)

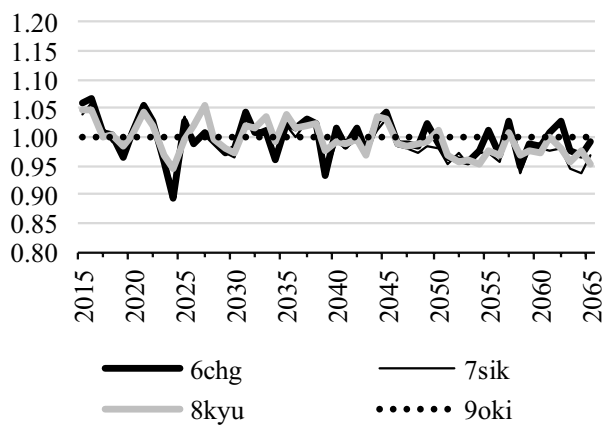

on Eq. (9), the same amount of money, as total subsidies to decrease $\mathrm{CH}_{4}$ emissions, is collected as carbon tax from all industries, including rice sector, in accordance with each industry's $\mathrm{CO}_{2}$ emission. ${ }^{5}$ The settings for MSD are the same as in Case 2.

Exogenous variables are set as follows in all cases: The growth rate of the population used as labor in each region is based on projections from the National Institute of Population and Social Security Research. Government savings, foreign savings, and regional money transfers are fixed at the present levels as noted in the social accounting matrix. The Japanese economy's technological growth rate is assumed as $0 \%$ per year to simplify the simulation.

\section{Results}

\section{The influence of climate change (Case 1 versus Case 0)}

Figure 5 illustrates the chronological changes in relative TFP ratios, calculated according to Eq. (2) and used for Cases 1 to 3 , from 2015 to 2065 . The annual TFP levels fluctuate due to changes in climate conditions. Okinawa's TFP was assumed to remain at the same level, as its change in rice production was negligible.

On average, the TFP in the northeastern regions-Hokkaido and Tohoku-increased even under climate change conditions, while the southwestern regions-Kanto, Chubu, Kinki, Chugoku, Shikoku, and Kyushu-experienced a decrease in TFP. This occurred because the temperature in the southwestern regions surpassed the threshold temperature for many years. Specifically, the degrees of decrease in Chubu and Kinki were almost the same as in Kyushu. Although Chubu and Kinki are located at higher latitudes

\footnotetext{
5 The carbon tax is calculated as $10.5 \times 10^{-4}(=1333 / 1,275,000)$, where 1333 ( $\$$ million) is $V_{\mathrm{CH} 4}$, and 1,275,000 (thousand tons) is the total amount of $\mathrm{CO}_{2}\left(\mathrm{O}_{\mathrm{CO} 2}\right)$ produced from all Japanese industries.
}

than Kyushu, the temperature increase under climate change was relatively high, and few high temperature-resistant rice varieties are grown in these regions. The TFP fluctuations in each region signify that future climate change could involve instances of cold weather as well as excessively high temperatures.

Figure 6 illustrates the influences of climate change (Case $1-$ Case 0 ) on gross rice production corresponding to the total production quantity (q_rice); rice prices ( $\mathrm{p} \_$rice); rice farmers' nominal income (inc_rice) ${ }^{6}$; gross regional production (GRP); equivalent variation (EV) indicating the social welfare level; and $\mathrm{CO} 2$ emissions (CO2). For brevity, the average values of every 15-year period-noted as "early term" (2021-2035), "midterm" (2036-2050), and "later term" (2051-2065)—were plotted for these target variables.

The entire country's (q_rice) increased due to climate change until approximately 2050, but subsequently decreased in accordance with TFP changes. Each region's (q_rice) increased in Hokkaido and Tohoku and chronologically declined in other regions. However, the changes in each region were canceled out and the nationwide changes lessened.

Rice prices moved almost inversely with an increase in production. As the (q_rice) includes inter-regional trade, price movements in each region were affected by neighboring regions. In particular, many imports from Tohoku occurred in the Kanto region; thus, the rice prices in this region did not increase in spite of the decrease in its own (q_rice).

Rice farmers' nominal income (inc_rice) in most regions declined until around 2050 to reflect rice price changes, then subsequently rose, but was still lower than the present level. As rice is a type of necessary good, the

\footnotetext{
${ }^{6}$ Farmers' nominal income is calculated by nominal net rice production as: inc_rice ${ }_{r}=w_{r} \cdot \mathrm{LS}_{\mathrm{pady}, r}+\mathrm{pf}_{r} \cdot \mathrm{FS}_{\mathrm{pady}, r}$, where pf is the rental price of farmland. Unlike the precise definition of the textbook, inc_rice defined here includes the wage and land rent payments to the non-rice farmers due to the limitation of the model's settings.
} 


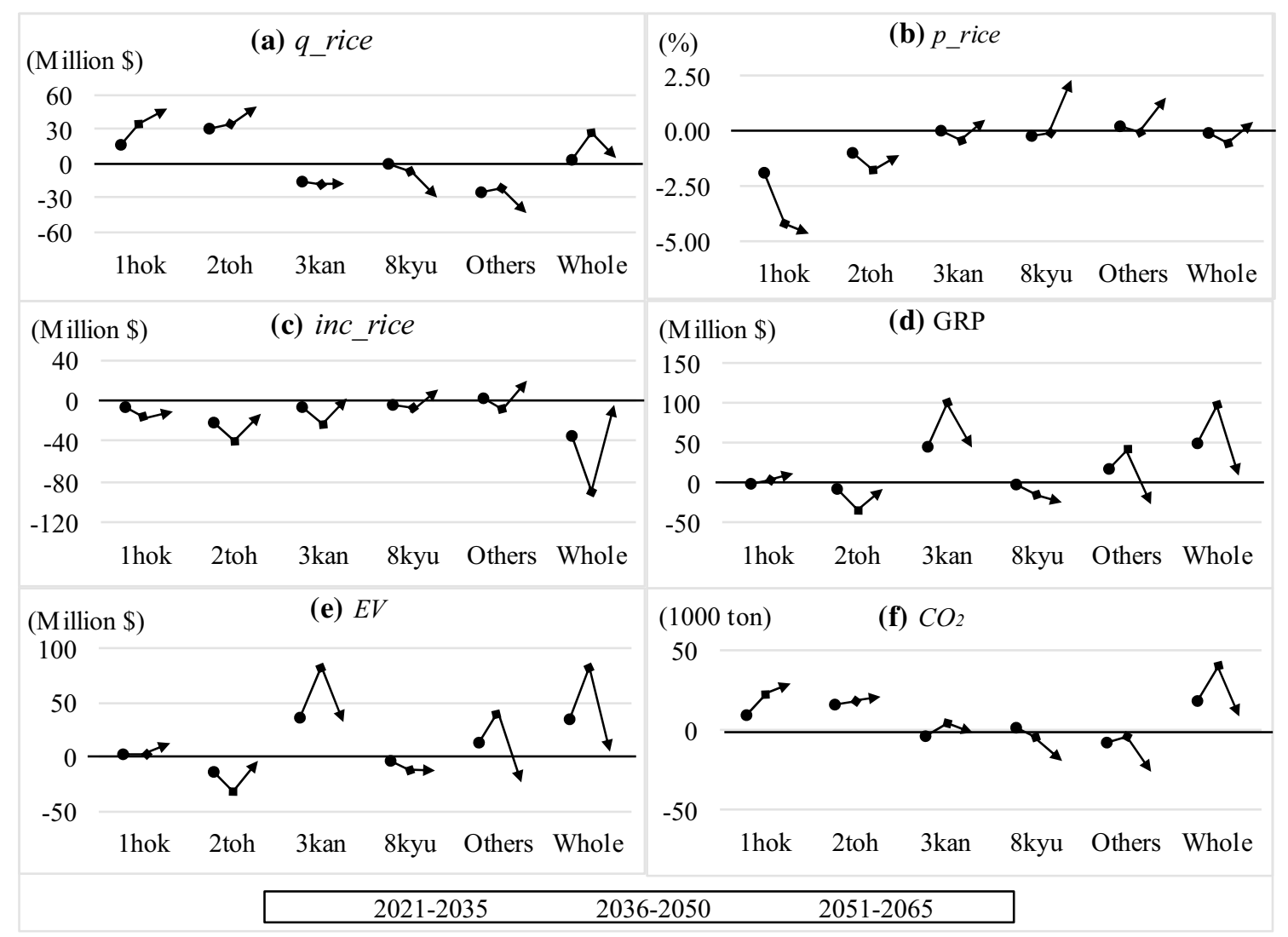

Fig. 6 Influences of climate change by variable and region. Note: The dots indicate the average level of difference between Case 1 and Case 0 in each variable for 15 years. The characters on the horizontal axis are the same as the legend of Fig. 5. Five regions-Chubu, Kinki,
Chugoku, Shikoku, and Okinawa-were merged into an "Others" group, as they have similar tendencies in variable changes, and the average values are relatively small in these regions price elasticity of demand is small; conversely, the change in price is large relative to the changes in demand. Therefore, rice farmers' (inc_rice) was greatly influenced by price changes rather than rice production.

When the rice sector's productivity increased (or decreased), this positive (or negative) influence expanded to other industries through labor and capital markets. Consequently, fluctuations in GRP, which corresponds to the total added value across all industries, became greater than the production changes in the rice sector. The average GRP growth rates in many regions-except for Tohoku and Kyushu - were positive until the midterm and became negative afterward. The GRP across the entire country (the GDP) increased due to climate change during all periods. The changes in EV exhibited a similar tendency as the GRP. $\mathrm{CO}_{2}$ emissions showed similar changes to (q_rice), as climate change was assumed to only affect the rice production and change $\mathrm{CO}_{2}$ emissions from this sector.
Overall, it can be posited that climate change will cause decreases in rice prices and rice farmers' nominal income because of bumper harvests until approximately 2050 .

\section{The effects of MSD and environmental subsidies with a carbon tax (Cases 2 and 3 versus Case 1)}

Figure 7 illustrates the effects of voluntary prolonging MSD under climate change (Case 2) as compared to Case 1 which only involves climate change. The values were calculated by subtracting Case 1 from Case 2 to demonstrate the policy measures' net effects.

Prolonging MSD caused the rice yield per area to decrease in all regions, but this measure caused a decrease in consumption due to increased rice prices, wages, and the rental prices of capital stocks. The characteristics of some farmlands changed as farmers planted other crops, and inter-regional trade increased. Consequently, the supply and demand equilibrium amounts (q_rice) decreased in all regions with regional differences, and especially in Tohoku. 
Fig. 7 Effects of voluntary prolonging MSD (Case 2). Note: The q_rice, p_rice, inc_rice, and GRP, respectively, signify the total rice production, rice prices, rice farmers' nominal income, and gross regional production. The characters at the horizontal axis are the same as those in Fig. 6
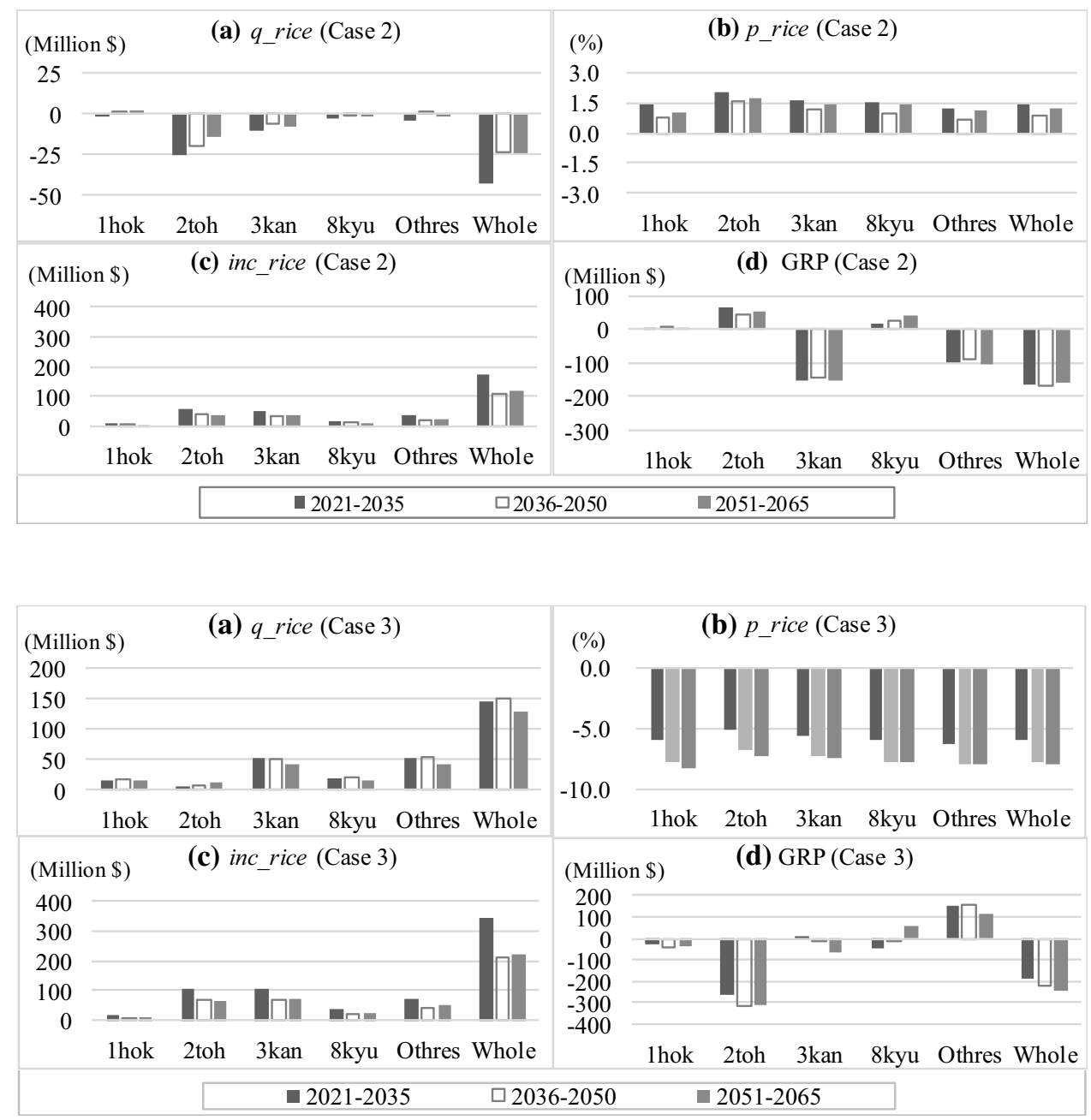

Fig. 8 Effects of MSD and the environmental subsidy with carbon tax (Case 3). Note: The variables and characters are the same as those in Fig. 7
A large decrease in Tohoku occurred for two reasons: First, the rice production in this region was substantial, and a decrease of 5\% in its rice yield, the same as in other regions, led to a significant difference in production amounts. Second, a decrease in other regions' demand caused a decrease in inter-regional transfers from Tohoku, where the rice sector was a primary source of funds acquisition.

This voluntary measure caused rice production to decrease across the entire country and rice prices to increase. Rather than causing production volume changes, rice farmers' nominal income increased following the same trends as the price changes. Implementing only the MSD measure caused a decrease in the nationwide GRP (GDP). Consequently, the MSD measure prevented a decrease in rice farmers' nominal income, which was decreased by climate change, although actual production was negatively impacted.

Figure 8 illustrates the effects of the policy mix-both prolonging MSD and the environmental subsidies with a carbon tax-as simulated in Case 3. As in the previous figures, this figure calculates the difference between Cases 3 and 1 to exclude other influences.
This policy mix reveals decreased negative impacts from only prolonging MSD (Case 2) on the production side. Further, rice production increased nationwide, and rice prices decreased. The nominal income increased across all regions owing to subsidies in spite of the price decrease. However, GDP (whole regions' GRP total) decreased due to a carbon tax. The negative impact of carbon tax on GRP was severe in Tohoku, as many energy intensive industries are located. Even so, this policy mix eliminates the disadvantages in rice production caused by prolonging MSD, and the negative impact on GDP is not so big, accounting for only $0.004 \%$ of Japan's total GDP.

A comparison between Figs. 7 and 8 suggests the net effects of environmental subsidies with a carbon tax, because a difference between these figures corresponds to a difference between Cases 2 and 3 and removes influences of MSD measures. From such comparison, it can be found that changes in GDP in Fig. 8 marked lower level than in Fig. 7, showing negative economic benefit in the case of only environmental subsidies with a carbon tax. Since the carbon tax decreased production in other 
Table 2 Changes in farmers' income per area due to policy measures

\begin{tabular}{lcccc}
\hline Item & Case 1 (\$/ha) & Case 2 (\$/ha) & Free ride (\$/ha) & Case 3 (\$/ha) \\
\hline Nominal income & & & & \\
Average (2021-2065) & 2884 & 2966 & 3011 & 3043 \\
Difference from Case 1 & 0 & 83 & 128 & 159 \\
\hline
\end{tabular}

The "free ride" values were calculated by multiplying Case 2 results by $1 / 0.95^{0.294}$. All values in this table include the environmental subsidy minus the carbon tax in each case; these values were then divided by the total area of paddy fields in Japan industries, this offset the increase in rice production and reduced the changes in GDP across the entire country. As will be demonstrated later, the country's $\mathrm{CO}_{2}$ emissions declined. Therefore, this measure brought about positive environmental benefit, but did not yield double dividends in the Japanese economy, as is consistent with Takeda's (2007) work.

\section{The possibility of a "free ride" and policy measures' environmental effects}

Table 2 illustrates rice farmers' nominal income per area. The nominal income in the "free ride" case was assumed as 1.015 times $\left(1 / 0.95^{0.294}\right)$ that in Case 2 . This number is the inverse value of the TFP change caused by the yield change, assuming that no decrease occurs in the free riders' yield from prolonging MSD.

Table 2 notes the level of nominal income per area occurred sequentially as Case $1<$ Case $2<$ Free Ride $<$ Case 3. In other words, and as Fig. 7 predicts, prolonging MSD prevented a decrease in rice farmers' nominal income by maintaining a higher level of rice prices if all farmers participate in this measure. As the "free ride" case became superior to Cases 1 and 2, the farmers' agreement to prolong MSD is always at risk due to the emergence of free riders. Although the concrete numbers are unknown, if several farmers become free riders and other farmers notice this change, the income level changes to Case 1 , which is the least ideal for all farmers. However, it is the most beneficial for farmers to be paid subsidies by participating in the prolonging of MSD among all possible policy measures. Thus, the incentive for "free rides" could be reduced by paying environmental subsidies to rice farmers.

Table 3 illustrates the total decrease in $\mathrm{CO}_{2}$ and $\mathrm{CH}_{4}$ emissions as a result of policy measures; the $\mathrm{CH}_{4}$ emissions have been converted to $\mathrm{CO}_{2}$-equivalent amounts with the efficiency coefficient for GHG emissions.

When only comparing $\mathrm{CO}_{2}$ emissions, the reduction in $\mathrm{CO}_{2}$ emissions from Case 3 was greater than in Case 2 because of the carbon tax. Reductions in $\mathrm{CH}_{4}$ emissions were the same in both cases, so the merits of prolonging MSD period and including an environmental subsidy with the carbon tax (as noted in Case 3) were environmentally superior to voluntary prolonging MSD shown by Case 2 .

\section{Summary, policy implications, and conclusion}

This study used a dynamic, spatial CGE model to measure the effects of prolonging mid-summer drainage (MSD) on rice production and regional economies. Environmental subsidies from carbon tax revenues were introduced to promote this MSD measure. Future situations were then simulated according to projection results from the MIROC global climate model under an RCP 8.5 scenario, which indicated the highest increase in temperature to parallel the recent growth trends among global economies.

The results demonstrate that an increased temperature decreases both rice prices and rice farmers' nominal income due to bumper harvests until approximately 2050 . Prolonging MSD in paddy fields effectively decreases methane gas $\left(\mathrm{CH}_{4}\right)$ emissions and prevents a decrease in farmers' income. However, some farmers can potentially increase their own incomes by avoiding MSD and gaining higher yields under higher rice prices, which are maintained by other farmers' voluntary participation in MSD. Therefore, strong motivation exists for some farmers to "free ride" this measure.

Environmental subsidies with a carbon tax are useful in motivating farmers to adopt MSD, and this can increase farmers' income without worsening the country's balance sheet, although such a policy cannot create "double-dividend" effects. Farmers who adopt the MSD measure and receive environmental subsidies gain a higher income than in the case of only climate change as well as in the case of

Table 3 Nationwide environmental effects after policy measures (Case 2 or $3-$ Case 1 )

\begin{tabular}{lll}
\hline Items & $\begin{array}{l}\text { Case } 2 \\
\left(1000 \text { eq. } \mathrm{CO}_{2} \text { ton }\right)\end{array}$ & $\begin{array}{l}\text { Case } 3 \\
\left(1000 \text { eq. } \mathrm{CO}_{2} \text { ton }\right)\end{array}$ \\
\hline $\mathrm{CO}_{2}$ & -61 & -470 \\
$\mathrm{CH}_{4}$ & $-41,750$ & $-41,750$ \\
\hline
\end{tabular}


voluntary participation in MSD, while GHG emissions, such as $\mathrm{CO}_{2}$ and $\mathrm{CH}_{4}$, can decrease nationwide with a small decrease in Japan's GDP.

Based on these findings, this study indicates that a mix of environmental policies, such as MSD and environmental subsidies, can be the key to obtaining environmental benefits with a simultaneous suitable economic benefit. Several tradeoffs exist in environmental policies, but a combination of such policy measures can ease these contradictions. Simulations involving the CGE model play an important role in planning and designing the best policy mix.

Another issue to consider involves how to monitor MSD performance, as easy technology sometimes causes problems with control and accountability. Further research and development should be conducted to address this matter. Additionally, analyses of other measures are important in addressing climate change, such as managing systems of rice intensification (SRIs). As SRI management requires intermittent and light irrigation and can be applied in other locations, such as African countries (Kassam et al. 2011), SRI management can possibly decrease paddy fields' $\mathrm{CH}_{4}$ emissions more than conventional management. If field experiment data on $\mathrm{CH}_{4}$ emissions becomes available, the CGE analysis employed here could verify SRI management's usefulness as a worldwide mitigation measure.

Many issues also remain for further study. First, the model must be improved to simulate more realistic situations. For example, important and noteworthy issues used in the dynamic stochastic general equilibrium model include an installation of forward-looking type assumptions, which will allow consumers to prepare for these future changes in advance. It is also necessary to renew and improve MSD field data relative to other countries, and especially Asian countries, in which rice production dominates.

Acknowledgements This study was supported by the Grant-in-Aid for Scientific Research 16H04991, 16KT0036, and the Social Implementation Program on Climate Change Adaptation Technology (Ministry of Education, Science, Sports and Culture). The crop model in this paper was advised by Dr. Toshichika Iizumi (NARO), and English language editing was supported by Editage (www.editage.jp). The authors greatly appreciate their support.

Open Access This article is distributed under the terms of the Creative Commons Attribution 4.0 International License (http://creativeco mmons.org/licenses/by/4.0/), which permits unrestricted use, distribution, and reproduction in any medium, provided you give appropriate credit to the original author(s) and the source, provide a link to the Creative Commons license, and indicate if changes were made.

\section{Appendix}

The CHI and CQI are, respectively, calculated from the crop growth and crop quality models, which were both estimated by Kunimitsu et al. (2015) using climate conditions, such as temperature and solar radiation during planting periods. The CFI is calculated using the maximum precipitation from August to October; specifically,

$$
\begin{aligned}
\text { CHI/SR7_9 } 9_{r, t}= & \beta_{0}^{\prime}+\beta_{1}^{\prime} \mathrm{TM} 7_{r, t}+\beta_{2}^{\prime} \mathrm{TM} 7_{r, t}^{2}+\beta_{3}^{\prime} \mathrm{TM} 8_{r, t}+\beta_{4}^{\prime} \mathrm{TM} 8_{r, t}^{2} \\
& +\beta_{5}^{\prime} \mathrm{TM} 9_{r, t}+\beta_{6}^{\prime} \mathrm{TM}_{r, t}^{2}+\varepsilon_{r, t}^{\prime},
\end{aligned}
$$

$$
\begin{aligned}
\mathrm{CQI}_{r, t}= & \beta_{0}^{\prime \prime}+\beta_{1}^{\prime \prime} \mathrm{SR} 7_{r, t}+\beta_{2}^{\prime \prime} \mathrm{SR} 8_{r, t}+\beta_{3}^{\prime \prime} \mathrm{ABS}\left(T L 7_{-} 8_{r, t}-19.34\right) \\
& +\beta_{4}^{\prime \prime} \mathrm{DYR}_{r, t}+\varepsilon_{r, t}^{\prime \prime}
\end{aligned}
$$

$\mathrm{CFI}_{r, t}=\max \left(\right.$ Rain89 $\left._{r, t, \mathrm{day}}\right)$,

where SR7_9, SR7, and SR8 are the average solar radiation from July to September, in July, and in August, respectively; TM7, TM8, TM9, and TL7_8 are the daily average temperatures in July, August, and September, and the average daily minimum temperature from July to August, respectively; DYR is the dummy variable that is 1 for the negative spikes, showing a rapid drop of $-20 \%$ in a specific year and rapid recovery the following year, and 0 otherwise; Rain 89 is the daily precipitation during August and September, which is typhoon season in Japan.

The estimated coefficients of Eq. (10) from the panel data (38 prefectures, with a time series spanning from 1979 to 2010 ) were $\beta^{\prime}{ }_{0}=-38.58880, \beta^{\prime}{ }_{1}=1.651944$, $\beta^{\prime}{ }_{2}=-0.035587, \beta^{\prime}{ }_{3}=1.822283, \beta^{\prime}{ }_{4}=-0.040967$, $\beta^{\prime}{ }_{5}=0.726466$, and $\beta^{\prime}{ }_{6}=-0.011593$, indicating the quadratic curvature relative to temperature. Further, the estimated coefficients of Eq. (11) from the $38 \times 31$ panel data were $\beta^{\prime \prime}{ }_{0}=54.79937, \beta^{\prime \prime}{ }_{1}=0.646943, \beta^{\prime \prime}{ }_{2}=0.940363$, $\beta^{\prime \prime}{ }_{3}=-6.703061$, and $\beta^{\prime \prime}{ }_{4}=-39.06254$, indicating a rooftop-shaped curvature regarding temperature. All estimated coefficients in Eqs. (10) and (11) were significant compared to the $t$-statistic values at the $0.1 \%$ level of probability. The adjusted $R$-squared values were 0.69 (Eq. 10) and 0.48 (Eq. 11), the $F$-statistics of redundant fixed-effects tests were 39.0 (Eq. 10) and 14.3 (Eq. 11) at a $0.1 \%$ level of significance, and the Hausman's test Chi-squared values were 212.5 (Eq. 10) and 16.5 (Eq. 11) at a $0.1 \%$ level of significance, demonstrating the fixed-effects model's superiority.

\section{References}

Ban K (2007) Development of the multi-regional dynamic computable general equilibrium model in Japan. In: RIETI discussion paper series 07-J-043:1-52 (in Japanese)

Cabinet Office of Japan (2016) National accounts. Cabinet Office of Japan, Tokyo (in Japanese)

Calzadilla A, Rehdanz K, Tol RSJ (2011) Water scarcity and the impact of improved irrigation management: a computable general equilibrium analysis. Agric Econ 42:305-323 
Ekins P, Barker T (2001) Carbon taxes and carbon emissions trading. J Econ Surv 15(3):325-376

Furuya J, Kobayashi S, Yamauchi K (2014) Impacts of climate change on rice market and production capacity in the Lower Mekong Basin. Paddy Water Environ 12(2):255-274

Iizumi T, Yokozawa M, Nishimori M (2009) Parameter estimation and uncertainty analysis of a large-scale crop model for paddy rice: application of a Bayesian approach. Agric For Meteorol 149:333-348

Itoh M, Sudo S, Mori S, Saito H, Yoshida T, Shiratori Y, Suga S, Yoshikawa N, Suzue Y, Mizukami H, Mochida T, Yagi K (2011) Mitigation of methane emissions from paddy fields by prolonging midseason drainage. Agric Ecosyst Environ 141:359-372

K-1 Model Developers (2004) K-1 coupled model (MIROC) description. In: Hasumi H, Emori S (eds) K-1 technical report 1. Center For Climate System Research, University of Tokyo, Tokyo, pp $1-34$

Kassam A, Stoop W, Uphoff N (2011) Review of SRI modifications in rice crop and water management and research issues for making further improvements in agricultural and water productivity. Paddy Water Environ 9(1):163-180

Kawase A, Kitaura Y, Hashimoto K (2003) Environmental tax and the double dividend: a computational general equilibrium analysis. Public Choice Studies 41:5-23 (in Japanese)

Koike A, Naka Y (2014) Examination of time stability of Armington elasticity in Japan. J Jpn Soc Civ Eng 70(5):161-171 (in Japanese)

Kunimitsu Y (2015) Regional impacts of long-term climate change on rice production and agricultural income: evidence from computable general equilibrium analysis. Jpn Agric Res Q 49(2):173-185

Kunimitsu Y (2018) Effects of restoration measures from the east Japan earthquake in the Iwate coastal area: application of a DSGE model. Asia-Pac J Reg Sci 2:317-335

Kunimitsu Y, Kudo R, Iizumi T, Yokozawa M (2015) Technological spillover in Japanese rice productivity under long term climate change: evidence from the spatial econometric model. Paddy Water Environ 14(1):131-144

Lee H (2009) The impact of climate change on global food supply and demand, food prices, and land use. Paddy Water Environ $7: 321-331$
Masui T (2005) Policy evaluation under environmental constraints using a computable general equilibrium model. Eur J Oper Res 166(3):843-855

Ministry of Agriculture, Forestry and Fisheries (MAFF) (2009-2018) Statistics on farmland and cultivated land area: 2008-2017. Ministry of Agriculture, Forestry and Fisheries, Tokyo (in Japanese)

Ministry of Economy, Trade and Industry (METI) (2009) 2005 Regional input-output basic classification table. Ministry of Economy, Trade and Industry, Tokyo (in Japanese)

Ministry of Economy, Trade and Industry (METI) (2010) 2005 Interregional input-output table. Ministry of Economy, Trade and Industry, Tokyo (in Japanese)

Miyagi T (2012) An application of the DSGE model with independent transport sector to highway project evaluation. J Jpn Soc Civ Eng 68(4):291-304

Narayanan GB, Walmsley LT (2008) Global trade, assistance, and production: The GTAP 7 data base. Center for Global Trade Analysis, Purdue University, West Lafayette

National Institute for Environmental Study (NIES) (2019) Embodied energy and emission intensity data for Japan using Input-Output tables (3EID) 2011. http://www.cger.niesgo.jp/publications/repor t/d031/jpn/page/data_file.htm. Accessed 14 March 2019

Palatnik RR, Roson R (2012) Climate change and agriculture in computable general equilibrium models: alternative modeling strategies and data needs. Clim Change 112:1085-1100

Rutherford T (1999) Applied general equilibrium modeling with MPSGE as a GAMS subsystem: an overview of the modeling framework and syntax. Comput Econ 14:1-46

Saito K (1996) Economic effects of minimum access to the rice market. J Rural Econ 68(1):9-19 (in Japanese)

Takeda S (2007) The double dividend from carbon regulations in Japan. J Jpn Int Econ 21(3):336-364

Tsuchiya K, Koike A, Akiyoshi S (2005) Discussion on the spatial substitution elasticity of inter-regional trade in SCGE model. In: 19th Annual conference of applied regional science conference in Meikai University (in Japanese) 